\title{
Analisis Regresi Logistik Ordinal Pada Tingkat Kepuasaan Pengguna Jasa Terhadap Pelayanan di Bandara Internasional Sam Ratulangi Manado
}

\author{
Ninda Wahyuni Paputungan ${ }^{1}$, Yohanes A. R. Langi ${ }^{2}$, Jantje D. Prang ${ }^{3 *}$ \\ ${ }^{1,2,3}$ Program Studi Matematika, Fakultas Matematika dan Ilmu Pengetahuan Alam, \\ Universitas San Ratulangi Manado \\ *corresponding author email : jdprang@yahoo.com
}

\begin{abstract}
Abstrak
Regresi logistik biner merupakan suatu metode analisis data yang digunakan untuk mencari hubungan antara variabel respon $(Y)$ yang bersifat biner atau dikotomus dengan variabel prediktor $(X)$ yang bersifat polikotomus. Tujuan dari penelitian ini untuk menganalisis tingkat kepuasan pengguna jasa terhadap kualitas pelayanan di bandara Internasional Sam Ratulangi Manado. Terdapat 16 variabel independen dan 1 variabel dependen. Variabel independen terbagi atas 3 aspek yaitu 7 aspek pelayanan, 5 aspek keamanan, dan 4 aspek komersial, sedangkan variabel dependennya adalah penilaian bandara secara umum. Data yang digunakan dalam penelitian ini yaitu data primer dengan menyebarkan kuesioner kepada 100 responden di bandara. Metode yang dipakai pada penelitian ini adalah metode regresi logistik ordinal. Dari hasil penelitian menunjukan bahwa variabel yang berpengaruh secara signifikan terhadap kepuasan pengguna jasa di bandara adalah keteraturan kendaran masuk dan keluar, ketersediaan tempat duduk di bandara, dan ketersediaan customer care service di bandara. Variabel independen yaitu aspek pelayanan, aspek keamanan, dan aspek komersial mempengaruhi penilaian pelayanan secara umum sebesar $94.0 \%$. Berdasarkan odds rasio dari 100 responden diketahui peluang pengguna jasa menilai pelayanan di Bandara Internasional Sam Ratulangi Manado dengan skala penilaian baik adalah 0.52 , Peluang untuk skala penilaian cukup 0.46 , dan peluang 0.02 untuk skala penilaian kurang baik.
\end{abstract}

Kata kunci : Regresi Logistik Ordinal, Rasio Odds, Kepuasan Pengguna Jasa

\section{Ordinal Logistics Regression Analysis in the Service User Statisfaction Level Toward Service at Sam Ratulangi International Airport Of Manado}

\begin{abstract}
Binary logistic regression is a method of data analysis used to find the relationship between the response variable $(Y)$ that is binary or dichotomous with the predictor variable $(X)$ which is polikotomus.The purpose of this researcher for analyze of user statisfaction service level toward the service at Internasional of Sam Ratulangi airport of Manado City. There are 16 independent variables and 1 dependent variable. The independent variable devided on 3 aspects, and 4 commercial aspects, meanwhile the dependent variable is the airport estimation in general. The data which used in this researcher are primary data by distribusing questionnaires to 100 respondents at the airport. The method used is ordinal logistics regression method. From the result of researcher show that the variables which significantly influence the statisfaction of service user at the airport is regularity of vehicles in and out, availability of sit place, and availability of costumer care service in the airport. The independent variable is attendances aspect, security aspect, and commercial aspect of the influence estimation generally affect the valuation of $94.0 \%$. Besade on odds ratio of 100 respondences, known the apportunity of user service assess of attendance at Internasional of Sam Ratulangi airport of Manado City with good assessmentt scale was 0.52 , enough apportunities to scale ratings of 0.46 and 0.02 for scale apportunities less kind.
\end{abstract}

Keywords : Ordinal Logistic Regression, Odds Ratio, Service User Satisfaction

\section{Pendahuluan}

Transportasi udara yaitu pesawat terbang merupakan transportasi angkutan tercepat di bandingkan dengan transportasi lainnya dan memerlukan biaya untuk memakainya, karena memiliki teknologi yang lebih canggih. PT. Angkasa Pura (Persero) adalah sebuah perusahaan Badan Usaha 
Milik Negara (BUMN) yang bertujuan untuk memberikan pelayanan lalu lintas udara dan bisnis bandar udara di Indonesia yang beroperasi memberikan pelayanan pada kawasan Indonesia bagian tengah dan kawasan Indonesia bagian timur [1].

Regresi logistik banyak digunakan secara luas pada bidang kedokteran, ilmu sosial, dan bahkan pada bidang pemasaran. Regresi logistik ordinal di gunakan untuk menganalisis variabel terikat yang mempunyai skala ordinal yang terdiri atas tiga kategori atau lebih. Variabel terikat yang dapat disertakan dalam model berupa data kategori atau kontinu yang terdiri atas dua variabel atau lebih [2].

Pada penelitian ini menggunakan regresi logistik ordinal. Regresi logistik ordinal digunakan untuk mengetahui lebih jauh hubungan antara kepuasan penumpang pesawat terbang terhadap kualitas pelayanan di bandara, dengan cara melakukan penelitian mengenai analisis tingkat kepuasan penumpang pesawat terbang terhadap pelayanan di Bandara Internasional Sam Ratulangi Manado.

\section{Regresi Logistik}

Regresi logistik merupakan analisis yang digunakan untuk melihat hubungan antara variabel respon yang bersifat kategorik (kualitatif) dan variabel-variabel prediktor yang bersifat nominal atau ordinal (kualitatif) maupun interval atau rasio (kuantitatif) [3].

Regresi logistik biner merupakan suatu metode analisis data yang digunakan untuk mencari hubungan antara variabel respon $(Y)$ yang bersifat biner atau dikotomus dengan variabel prediktor $(X)$ yang bersifat polikotomus. Keluaran dari variabel respon $(Y)$ terdiri dari 2 (dua) kategori yang biasanya dinotasikan dengan $Y=1$ (sukses) dan $Y=0$ (gagal). Bentuk umum regresi logistik adalah sebagai berikut [4].

$$
\pi(X)=\frac{\exp \left(\beta_{0}+\beta_{1} X_{1}+\cdots+\beta_{k} X_{k}\right)}{1+\exp \left(\beta_{0}+\beta_{1} X_{1}+\cdots+\beta_{k} X_{k}\right)}
$$

Kemudian dilakukan transformasi logit untuk menyederhanakan persamaan 1 dalam bentuk logit sebagai berikut.

$$
\mathrm{g}(\mathrm{x})=\ln \left[\frac{\pi(X)}{1-\pi(X)}\right]=\beta_{0}+\beta_{1} x_{1}+\beta_{2} x_{2}+\ldots+\beta_{k} x_{k}
$$

Jika terdapat $J$ kategori respon maka model logistik ordinal yang terbentuk adalah:

$$
\begin{aligned}
& \operatorname{Logit}\left(Y_{1}\right)=\operatorname{In}\left(\frac{\mathrm{Y} 1}{1-\mathrm{Y} 1}\right)=\theta_{1}+\beta_{1} X_{1}+\beta_{2} X_{2}+\cdots+\beta p X p \\
& \operatorname{Logit}\left(Y_{2}\right)=\operatorname{In}\left(\frac{\mathrm{Y} 2}{1-\mathrm{Y} 2}\right)=\theta_{2}+\beta_{1} X_{1}+\beta_{2} X_{2}+\cdots+\beta p X p \\
& \vdots \\
& \operatorname{Logit}\left(Y_{J-1}\right)=\operatorname{In}\left(\frac{\mathrm{YJ}-1}{1-\mathrm{YJ}-1}\right)=\theta_{J-1}+\beta_{1} X_{1}+\beta_{2} X_{2}+\cdots+\beta p X p \\
& Y_{j}(X)=\pi_{1}(X)+\pi_{2}(X)+\cdots+\pi_{j}(X)=\frac{e^{\theta j} \beta^{T x}}{1+e^{\theta j} \beta^{T X}}, j=1,2, \ldots J-1
\end{aligned}
$$

Model diatas merupakan model logit kumulatif sebab odds rasio kejadian $(Y \leq j)$ adalah independen pada setiap indikator kategori.

a. Pengujian Parameter Secara Keseluruhan (Overall Test)

Statistik uji-G digunakan untuk menguji peranan variabel penjelas di dalam model secara bersama-sama.

$$
G=-2 \ln \left[\frac{\text { likelihood }(\text { Model } B)}{\text { likelihood }(\text { Model } A)}\right]
$$

Keterangan model $\mathrm{B}=$ model yang hanya terdiri dari konstanta saja dan model $\mathrm{A}=$ model lengkap (model dengan variabel prediktor). Hipotesis dari persamaan diatas adalah $\mathrm{H}_{0}: \beta_{1}=\beta_{2}=\ldots=\beta_{p}=0$ dan $\mathrm{H}_{1}$ : minimal terdapat $\beta p \neq 0$. Kriteria ini mengambil taraf nyata $\alpha$ maka $H_{0}$ ditolak jika $G>$ $\chi^{2}(\alpha, v)$ dimana $v$ adalah banyaknya variabel prediktor [3].

b. Pengujian Parameter Secara Parsial

Pegujian ini dilakukan untuk memeriksa kemaknaan koefisien $\beta$ secara parsial dengan menggunakan Statistik uji, yang digunakan Uji-Wald. 


$$
W=\frac{\widehat{\beta}_{k}}{S E\left(\beta_{k}\right)}
$$

Hipotesis $\mathrm{H}_{0}: \mathrm{H}_{1}=0$ (parameter dalam model, untuk variabel prediktor ke- $k$ dengan kategori ke$i$ tidak berarti) dan hipotesis alternatifnya $H_{1}: \beta_{k i} \neq 0$ (parameter dalam model, untuk variabel prediktor ke- $k$ dengan kategori ke- $i$ berarti). Daerah penolakan $\mathrm{H}_{0}$ adalah $|\mathrm{W}|>\mathrm{Z}_{\alpha / 2}$ atau $\mathrm{W}^{2}>>$ $\chi^{2}{ }_{(\alpha, 1)}$, dengan derajat bebas $\mathrm{v}$ atau $\mathrm{p}$-value $<\alpha[3]$.

c. Uji Kelayakan Model

Statistik uji Deviance didefinisikan dengan rumus :

$$
\mathrm{D}=-2 \sum_{i=1}^{n}\left[Y_{i} \ln \left(\frac{\widehat{\pi}_{i}}{y_{i}}\right)+\left(1-Y_{i}\right) \ln \left(\frac{1-\widehat{\pi}_{i}}{1-y_{i}}\right)\right]
$$

dengan $\hat{\pi}=\frac{\exp \left(g\left(x_{i}\right)\right)}{1+\exp \left(g\left(x_{i}\right)\right)}, \mathrm{g}\left(\mathrm{x}_{i}\right)=\beta_{0}+\beta_{1} \mathrm{x}_{i l}+\beta_{p} \mathrm{x}_{i p}, i=1,2, \ldots, \mathrm{n}$.

Statistik D akan mengikuti sebaran $\mathcal{X}^{2}$ dengan derajat bebas n-p. Kriteria keputusan yang di ambil yaitu menolak $\mathrm{H}_{0}$ jika $\mathrm{D}_{\text {hitung }}>\mathcal{X}_{\alpha(\mathrm{n}-\mathrm{p})}$.

d. Interpretasi

Regresi logistik juga menghasilkan rasio peluang (odds ratio) terkait dengan nilai setiap prediktor. Peluang (odds) dari suatu kejadian diartikan sebagai probabilitas hasil yang muncul yang dibagi dengan probabilitas suatu kejadian tidak terjadi. Secara umum, rasio peluang (odds ratio) merupakan sekumpulan peluang yang dibagi oleh peluang lainnya. Rasio peluang bagi prediktor diartikan sebagai jumlah relatif dimana peluang hasil meningkat (rasio peluang > 1) atau turun (rasio peluang < 1) ketika nilai variabel prediktor meningkat sebesar 1 unit [5].

\section{Metodologi Penelitian}

\subsection{Waktu dan Tempat Penelitian}

Penelitian dilakukan pada bulan Juni 2016. Tempat penelitian berupa pengambilan data kuesioner dilaksanakan di Bandara Internasional Sam Ratulangi Manado. Analisis data dilakukan di Laboratorium Statistika Program Studi Matematika Fakultas Matematika dan Ilmu Pengetahuan Alam Universitas Sam Ratulangi Manado.

\subsection{Populasi dan Sampel}

Populasi dalam penelitian ini adalah penumpang yang berangkat dari Bandara Internasional Sam Ratulangi Manado. Pengambilan sampel dilakukan secara purposive random sampling sebanyak 100 penumpang (responden) yang minimal 2 (dua) kali telah melakukan keberangkatan dari Bandara Internasional Sam Ratulangi Manado.

\subsection{Sumber Data}

Penelitian ini menggunakan data primer, dengan menyebarkan kuesioner kepada penumpang (responden) keberangkatan di Bandara Internasional Sam Ratulagi Manado. Variabel yang digunakan dalam penelitian ini adalah variabel tentang perilaku pengguna jasa sebagai variabel independen dan kepuasan pelanggan sebagai variabel dependen. Variabel independen terdiri atas 16 variabel yang terbagi kedalam 3 aspek yaitu 7 variabel aspek pelayanan, 5 variabel aspek keamanan dan 4 variabel aspek komersial sedangkan variabel dependennya yaitu penilaian pelayanan Bandara secara umum.

Tabel 1. Variabel Independen dan Dependen

\begin{tabular}{|l|l|}
\hline Variabel & \multicolumn{1}{c|}{ Pertanyaan } \\
\hline \multicolumn{2}{|c|}{ Variabel Bebas : Aspek Pelayanan } \\
\hline $\mathrm{X} 1$ & Keteraturan Kendaraan \\
\hline $\mathrm{X} 2$ & Fasilitas Pendukung \\
\hline $\mathrm{X} 3$ & Tempat Duduk \\
\hline $\mathrm{X} 4$ & Tempat Sampah \\
\hline $\mathrm{X} 5$ & Kebersihan Bandara \\
\hline $\mathrm{X} 6$ & Kebersihan Toilet \\
\hline $\mathrm{X} 7$ & Pengaturan Ketertiban Keberangkatan \\
\hline \multicolumn{2}{|c|}{ Variabel Bebas : Aspek Keamanan } \\
\hline $\mathrm{X} 8$ & Ruang Tunggu/Boarding Room \\
\hline $\mathrm{X} 9$ & Area Parkir \\
\hline
\end{tabular}




\begin{tabular}{|c|c|}
\hline Variabel & Pertanyaan \\
\hline X10 & Keberadaan Petugas \\
\hline X11 & Keramahan Petugas Keamanan \\
\hline X12 & Tingkat Kenyamanan di Bandara \\
\hline \multicolumn{2}{|c|}{ Variabel Bebas : Aspek Komersial } \\
\hline X13 & Ketersediaan Ruang Customer Care \\
\hline X14 & Keramahan Customer Care \\
\hline X15 & Loket Customer Care service \\
\hline X16 & Keramahan Petugas Boarding Pass \\
\hline \multicolumn{2}{|c|}{ Variabel Tak Bebas Pelayanan Global Bandara } \\
\hline Y & Penilaian Kepuasan Pelayanan Umum \\
\hline
\end{tabular}

\subsection{Tahapan Analisis Data}

Dalam penelitian ini menggunakan Analisis Regresi Logistik, yang akan di analisis adalah data primer yang di dapatkan melalui kuesioner. Tahapan analisisnya adalah sebagai berikut :

1. Penyusunan Instrumen

Penyusunan instrumen kuesioner untuk pertanyaan yang berupa aspek-aspek penelitian menggunakan 3(tiga) skala seperti pada tabel 2.

Tabel 2. Skala Kepuasan

\begin{tabular}{|c|c|}
\hline Skala & Keterangan \\
\hline 0 & Kurang Baik \\
\hline 1 & Cukup \\
\hline 2 & Baik \\
\hline
\end{tabular}

2. Pengumpulan Data dan Entry Data

Pengambilan data dari kuesioner yang dilakukan di Bandara Internasional Sam Ratulangi Manado, yaitu pada pagi hari pukul 05.30 - 11.00.

3. Analisis Deskriptif

Untuk melihat gambaran data secara umum pada tiap-tiap kuesioner yang telah di pilih oleh responden, analisis deskriptif disajikan dalam bentuk diagram pie.

4. Uji validitas dan Reliabilitas

Uji validitas dan reliabilitas digunakan untuk melihat kevaliditan suatu instrumen. Suatu instrumen dianggap valid, apabila mampu mengukur apa yang diinginkan.

5. Menyusun Model Regresi Logistik

Pembuatan model dilakukan menggunakan persamaan 3,4,5, dan 6.

6. Pengujian Model

Pengujian model dengan menggunakan Uji statistik G, Uji Wald, Uji Kelayakan Model dan koefisien determinasi.

7. Interpretasi Data

Model regresi logistik ordinal telah di uji dan hasil modelnya baik, signifikannya nyata maka data tersebut dapat diinterpretasikan dengan menggunakan Odds Ratio.

\section{Hasil dan Pembahasan}

\subsection{Deskripsi Penilaian Responden Terhadap Kualitas Pelayanan di Bandara Internasional Sam ratulangi Manado}

Penilaian responden terhadap aspek pelayanan menunjukan bahwa $32 \%$ responden menilai baik, untuk aspek keamanan 37\% responden menilai baik, dan aspek komersial 31\% responden menilai baik. Seperti disajikan pada gambar 1.

\subsection{Uji Keberartian Model}

Hasil analisis nilai G sebesar 132.655, dengan derajat kebebasan $(D F)=32$, kriteria penguji dilakukan dengan mengambil taraf nyata $\alpha=0.05$, nilai chi-kuadrat diperoleh $X^{2}{ }_{(0.05,32)}=46.194$, karena nilai statistik $G=132.655>46.194$ maka keputusannya tolak $\mathrm{H}_{0}$ dan terima $\mathrm{H}_{1}$. Kesimpulannya terdapat salah satu $\beta_{\mathrm{p}} \neq 0$, artinya terdapat salah satu variabel independen mempengaruhi variabel dependen. 


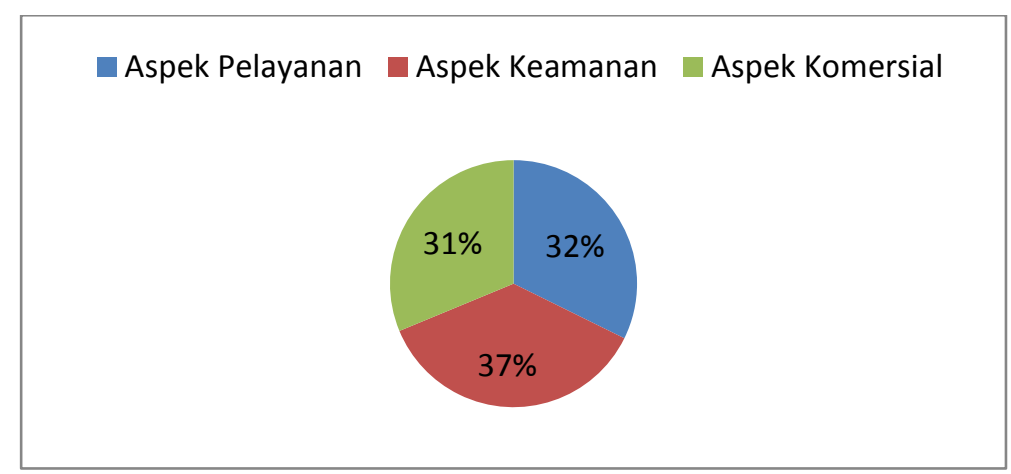

Gambar 1. Penilaian Responden Terhadap Aspek Pelayanan, Aspek Keamanan, dan Aspek Komersial.

\subsection{Uji Keberartian Parameter Secara Parsial}

Dalam uji parameter secara parsial atau uji masing-masing tahap awal yang dilakukan adalah pembentukan variabel dummy pada variabel independen yaitu $\mathrm{X}_{1}$ sampai dengan variabel independen $\mathrm{X}_{16}$. Selanjutnya mengetahui variabel apa saja yang berpengaruh terhadap dependen secara parsial, oleh karena itu dilakukan pembentukan model regresi logistik secara parsial.

Tabel 3. Model Regresi Logistik Secara Parsial

\begin{tabular}{|c|c|c|c|c|}
\hline No & Predictor & Coef & SE Coef & P-value \\
\hline 1 & $\begin{array}{l}\text { X1_D1 } \\
\text { X1_D2 }\end{array}$ & $\begin{array}{l}-2,73691 \\
-5,03762\end{array}$ & $\begin{array}{l}1,47551 \\
1,51309 \\
\end{array}$ & $\begin{array}{c}0,064 \\
0,01 \\
\end{array}$ \\
\hline 2 & $\begin{array}{l}\text { X2_D1 } \\
\text { X2_D2 }\end{array}$ & $\begin{array}{l}0,758732 \\
-1,21584 \\
\end{array}$ & $\begin{array}{l}1,25811 \\
1,21715 \\
\end{array}$ & $\begin{array}{l}0,546 \\
0,318 \\
\end{array}$ \\
\hline 3 & $\begin{array}{l}\text { X3_D1 } \\
\text { X3_D2 }\end{array}$ & $\begin{array}{l}-0,836716 \\
-2,31102 \\
\end{array}$ & $\begin{array}{c}0,823668 \\
0,77822 \\
\end{array}$ & $\begin{array}{l}0,310 \\
0,003\end{array}$ \\
\hline 4 & $\begin{array}{l}\text { X4_D1 } \\
\text { X4_D2 }\end{array}$ & $\begin{array}{r}-0,24744 \\
-1,75353 \\
\end{array}$ & $\begin{array}{l}1,04836 \\
1,03033 \\
\end{array}$ & $\begin{array}{l}0,813 \\
0,089 \\
\end{array}$ \\
\hline 5 & $\begin{array}{l}\text { X5_D1 } \\
\text { X5_D2 }\end{array}$ & $\begin{array}{l}-21,6646 \\
-23,9341 \\
\end{array}$ & $\begin{array}{l}4831,22 \\
4831,22 \\
\end{array}$ & $\begin{array}{l}0,996 \\
0,996\end{array}$ \\
\hline 6 & $\begin{array}{l}\text { X6_D1 } \\
\text { X6_D2 }\end{array}$ & $\begin{array}{c}-2,8816 \\
-4,27081 \\
\end{array}$ & $\begin{array}{l}1,38359 \\
1,40185 \\
\end{array}$ & $\begin{array}{l}0,037 \\
0,002\end{array}$ \\
\hline 7 & $\begin{array}{l}\text { X7_D1 } \\
\text { X7_D2 }\end{array}$ & $\begin{array}{l}-2,48606 \\
-4,20385\end{array}$ & $\begin{array}{l}1,16631 \\
1,18443 \\
\end{array}$ & $\begin{array}{l}0,033 \\
0,000\end{array}$ \\
\hline 8 & $\begin{array}{l}\text { X8_D1 } \\
\text { X8_D2 }\end{array}$ & $\begin{array}{l}-2,45998 \\
-4,66452\end{array}$ & $\begin{array}{l}1,49426 \\
1,51894\end{array}$ & $\begin{array}{l}0,100 \\
0,002\end{array}$ \\
\hline 9 & $\begin{array}{l}\text { X9_D1 } \\
\text { X9_D2 }\end{array}$ & $\begin{array}{c}-2,82168 \\
-3,8257\end{array}$ & $\begin{array}{l}1,19668 \\
1,20922 \\
\end{array}$ & $\begin{array}{l}0,018 \\
0,002\end{array}$ \\
\hline 10 & $\begin{array}{l}\text { X10_D1 } \\
\text { X10_D2 }\end{array}$ & $\begin{array}{l}-21,372 \\
-22,858 \\
\end{array}$ & $\begin{array}{l}5164,37 \\
5164,37 \\
\end{array}$ & $\begin{array}{l}0,997 \\
0,997 \\
\end{array}$ \\
\hline 11 & $\begin{array}{l}\text { X11_D1 } \\
\text { X11_D2 }\end{array}$ & $\begin{array}{c}-0,850941 \\
-1,7625 \\
\end{array}$ & $\begin{array}{l}0,892126 \\
0,855623\end{array}$ & $\begin{array}{l}0,340 \\
0,039 \\
\end{array}$ \\
\hline 12 & $\begin{array}{l}\text { X12_D1 } \\
\text { X12_D2 }\end{array}$ & $\begin{array}{r}-21,1798 \\
-23,9759 \\
\end{array}$ & $\begin{array}{l}4506,93 \\
4506,93 \\
\end{array}$ & $\begin{array}{l}0,996 \\
0,996 \\
\end{array}$ \\
\hline 13 & $\begin{array}{l}\text { X13_D1 } \\
\text { X13_D2 }\end{array}$ & $\begin{array}{l}-21,1715 \\
-23,0884 \\
\end{array}$ & $\begin{array}{l}4723,52 \\
4723,52 \\
\end{array}$ & $\begin{array}{l}0,996 \\
0,996 \\
\end{array}$ \\
\hline 14 & $\begin{array}{l}\text { X14_D1 } \\
\text { X14_D2 }\end{array}$ & $\begin{array}{l}-0,24747 \\
-1,75353 \\
\end{array}$ & $\begin{array}{l}1,04836 \\
1,03033 \\
\end{array}$ & $\begin{array}{l}0,813 \\
0,089 \\
\end{array}$ \\
\hline 15 & $\begin{array}{l}\text { X15_D1 } \\
\text { X15_D2 }\end{array}$ & $\begin{array}{c}-2,83711 \\
-4,706\end{array}$ & $\begin{array}{l}1,32351 \\
1,35823\end{array}$ & $\begin{array}{l}0,032 \\
0,001\end{array}$ \\
\hline 16 & $\begin{array}{l}\text { X16_D1 } \\
\text { X16_D2 }\end{array}$ & $\begin{array}{l}-2,89426 \\
-4,85036\end{array}$ & $\begin{array}{l}1,46455 \\
1,49438 \\
\end{array}$ & $\begin{array}{l}0,048 \\
0,001\end{array}$ \\
\hline
\end{tabular}


Variabel yang tidak signifikan tersebut dikeluarkan dari model dan dilakukan kembali pengujian regresi logistik ordinal secara keseluruhan dapat dilihat pada tabel 4 . Variabel yang digunakan adalah $\mathrm{X}_{1}$ keteraturan kendaraan masuk dan keluar dibandara, $\mathrm{X}_{2}$ ketersediaan fasilitas pendukung, $\mathrm{X}_{3}$ ketersediaan fasilitas tempat duduk dibandara, $\mathrm{X}_{6}$ kondisi/kebersihan toilet secara umum, $X_{7}$ pengaturan ketertiban departure/keberangkatan penumpang, $X_{8}$ kondisi keamanan ruang tunngu/boarding room, $\mathrm{X}_{9}$ kondisi keamanan di area parkir, $\mathrm{X}_{15}$ ketersediaan loket customer service maskapai penerbangan di bandara, dan $\mathrm{X}_{16}$ keramahan petugas boarding pass.

\subsection{Model Regresi Logistik}

Pada pengujian secara keseluruhan (overall test) ini, variabel yang dimasukkan adalah variabel-variabel yang telah signifikan pada pengujian parsial sebelumnya (pada tabel 3).

Tabel 4. Model Regresi Logistik Ordinal

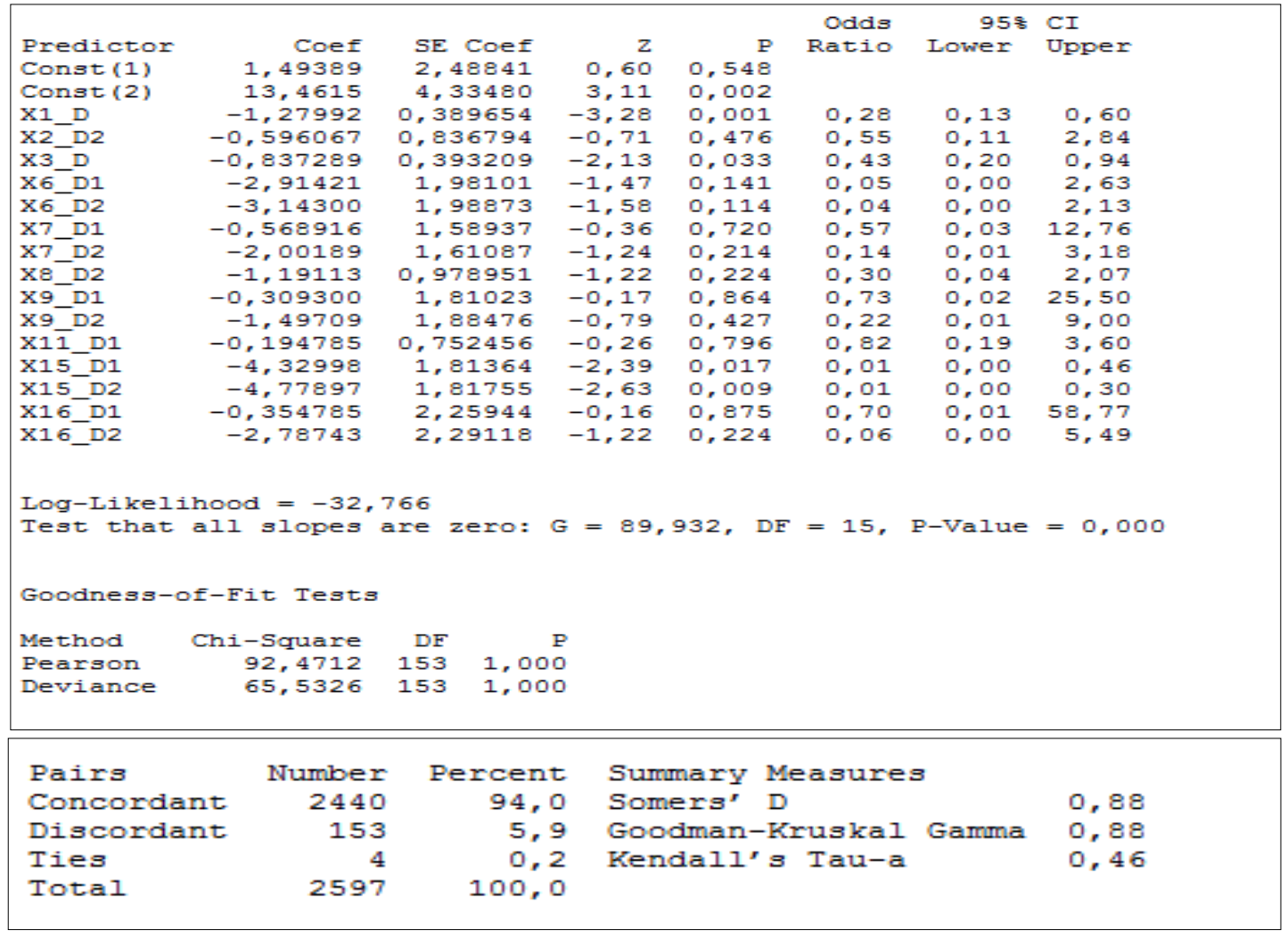

Tabel 4 menjelaskan bahwa terdapat 3 kemungkinan nilai $Y$ yaitu :
a. $Y_{i}=0$ jika $Y^{*}{ }_{i} \leq 1,493$
b. $Y_{i}=1$ jika $1,493<Y^{*}<13,461$
c. $Y_{i}=2$ jika $Y *_{i} \geq 13,461$

Model dugaan logit yang didapat adalah :
1. $\log \left(\frac{\widehat{\pi}_{1}}{1-\widehat{\pi}_{1}}\right)=1,493-1,279 \mathrm{X}_{1}-0,837 \mathrm{X}_{3}-4,329 \mathrm{X}_{15} \_\mathrm{D} 1-4,778 \mathrm{X}_{15} \_\mathrm{D} 2$
2. $\log \left(\frac{\widehat{\pi_{2}}}{1-\widehat{\pi_{2}}}\right)=13,461-1,279 \mathrm{X}_{1}-0,837 \mathrm{X}_{3}-4,329 \mathrm{X}_{15} \_\mathrm{D} 1-4,778 \mathrm{X}_{15} \mathrm{D} 2$

Pada tabel 4 untuk variabel X1_D, X3_D, X15_D1, dan X15_D2 memiliki nilai peluang masing-masing $0.1 \%, 3.3 \%, 1.7 \%$, dan $0.9 \%$. Hal ini memberikan arti bahwa variabel-variabel yang mempengaruhi peluang penilaian fasilitas pelayanan bandara secara umum adalah variabel keteraturan kendaraan masuk dan keluar bandara, ketersediaan fasilitas tempat duduk, dan ketersediaan loket customer servie maskapai penerbangan di bandara, dikarenakan variabel-variabel yang mempunyai signifikan p-value < taraf nyata yaitu 0.05 atau dengan kata lain tolak $\mathrm{H}_{0}$, sedangkan untuk variabel-variabel sisanya dapat dikatakan tidak berpengaruh secara signifikan terhadap tingkat kepuasan fasilitas pelayanan publik di Bandara Internasional Sam Ratulangi Manado. 
Uji kelayakan model (Goodness Of Fit) dilakukan untuk melihat apakah model regresi logistik ordinal yang didapat layak untuk digunakan. Hipotesis yang akan diuji adalah $\mathrm{H}_{0}$ : Model logit layak digunakan dan $\mathrm{H}_{1}$ : Model logit tidak layak digunakan. Diketahui nilai chi-square pada metode Deviance sebesar 65.5326, kriteria pengujiannya adalah tolak $\mathrm{H}_{1}$ bila nilai $\mathrm{p}$-value kurang dari $\alpha=0.05$. Uji Deviance pada tabel 5 didapat p-value sebesar 1.000. Keputusan yang di ambil adalah terima $\mathrm{H}_{0}$ karena nilai p-valuenya lebih besar dari 0.05 , yang artinya model regresi logistik pada tabel 5 layak digunakan.

\subsection{Interpretasi Model}

Berdasarkan total jawaban responden di Bandara Internasional Sam Ratulangi Manado di dapat hasil sebagai berikut :

Tabel 5. Frekuensi Jawaban Pada Kuesioner

\begin{tabular}{|l|c|c|c|}
\hline \multicolumn{1}{|c|}{ Skala } & $\begin{array}{c}\text { Frekuensi } \\
\text { Variabel Y }\end{array}$ & $\begin{array}{c}\text { Frekuensi Total } \\
\text { Jawaban }\left(\mathbf{X}_{\mathbf{1}}, \mathbf{X}_{\mathbf{2}}, \ldots . . \mathbf{X}_{\mathbf{1 6}}\right)\end{array}$ & Peluang \\
\hline Kurang Baik & 2 & 96 & 0,02 \\
\hline Cukup & 46 & 611 & 0,46 \\
\hline Baik & 52 & 893 & 0,52 \\
\hline Total & $\mathbf{1 0 0}$ & $\mathbf{1 6 0 0}$ & $\mathbf{1 , 0 0 0}$ \\
\hline
\end{tabular}

Nilai odds ratio untuk $\mathrm{X}_{1}$ keteraturan kendaraan masuk dan keluar di bandara sebesar $\exp (-1.279)=0.28$, yang berarti bahwa keteraturan kendaraan masuk dan keluar di bandara memiliki peluang 0.28 kali lebih kecil dari pada variabel lainnya terhadap tingkat kepuasan pelayanan publik di bandara. Nilai odds ratio untuk $\mathrm{X}_{3}$ ketersediaan fasilitas tempat duduk di bandara sebesar $\exp (-0.837)=0.43$, yang berarti bahwa fasilitas tempat duduk di bandara memiliki peluang $0.43 \mathrm{kali}$ lebih kecil dari pada variabel lainnya terhadap tingkat kepuasan pelayanan publik di bandara. Nilai odds ratio untuk $\mathrm{X}_{15}$ ketersediaan loket customer service maskapai penerbangan di bandara sebesar $\exp (-4.329)=0.01$ Nilai odds ratio untuk ketersediaan loket customer service maskapai penerbangan naik sebesar 0.01 terhadap tingkat kepuasan pelayanan publik di bandara

Berdasarkan tabel 4, untuk melihat keragaman peubah respon $\mathrm{Y}$ dapat dijelaskan oleh peubah penjelas X dengan melihat nilai persen pada Concordant. Pada penelitian ini diperoleh nilai sebesar $94.0 \%$ yang artinya sebesar 94.0\% keragaman peubah respon Y mampu dijelaskan oleh peubah penjelas $\mathrm{X}_{1}, \mathrm{X}_{2, \ldots}, \mathrm{X}_{16}$.

\section{Kesimpulan}

1. Model Regresi logistik ordinal untuk tingkat kepuasan fasilitas pengguna jasa di Bandara Internasional Sam Ratulangi adalah :

$$
\begin{aligned}
& \log \left(\frac{\widehat{\pi_{1}}}{1-\widehat{\pi_{1}}}\right)=1,493-1,279 \mathrm{X}_{1}-0,837 \mathrm{X}_{3}-4,329 \mathrm{X}_{15} \_\mathrm{D} 1-4,778 \mathrm{X}_{15} \_\mathrm{D} 2 \\
& \log \left(\frac{\widehat{\pi_{2}}}{1-\widehat{\pi}_{2}}\right)=13,461-1,279 X_{1}-0,837 X_{3}-4,329 X_{15 \_D 1}-4,778 X_{15} \text { D2 }
\end{aligned}
$$

Variabel yang berpengaruh terhadap kepuasan pengguna jasa terhadap pelayanan di Bandara Internasional Sam Ratulangi Manado adalah $\mathrm{X}_{1}$ keteraturan kendaraan masuk dan keluar di bandara, $\mathrm{X}_{3}$ ketersedian fasilitas tempat duduk di bandara, dan untuk $\mathrm{X}_{15}$ ketersediaan loket customer service maskapai penerbangan di bandara.

2. Berdasarkan odds ratio dari 100 responden peluang pengguna jasa menilai fasilitas pelayanan secara umum di Bandara Internasional Sam Ratulangi Manado dengan peluang untuk skala penilaian baik adalah 0.52 , peluang untuk skala penilaian cukup 0.46 , dan peluang 0.02 untuk skala kurang baik.

\section{Daftar Pustaka}

[1] Sora, N. 2015. Pengertian Transportasi dan Fungsinya. http://www.pengertianku.net/2015/12/pengertian-transportasi-dan-fungsinya-maupuncontohnya.html [diakses 20 Desember 2015].

[2] Agresti, A. 1990. Categorical Data Analysis. New York : JohnWiley \& Sons.Inc. 
[3] Sepang, F. 2012. Penerapan Regresi Logistik untuk Menentukan Faktor-Faktor yang Mempengaruhi Pemilihan Jenis Alat Kontrasepsi di Kecamatan Modayag Barat. Universitas Sam Ratulangi. Manado. Jurnal MIPA 1(1) : 1-5.

[4] Hosmer, D.W and S. Lemeshow. 2000. Applied Logistic Regression Second Edition. New York: John Wiley and Sons, Inc.

[5] Albana, M. 2013. Aplikasi Regresi Logistik Ordinal Untuk Menganalisa Tingkat Kepuasaan Pengguna Jasa Terhadap Pelayanan di Stasiun Jakarta Kota [Skripsi]. Universitas Pakuan. Bogor. 